\title{
Quantifying the impact of current and future concentrations of air pollutants on respiratory disease risk in England
}

\author{
Francesca Pannullo $^{1^{*}}$ (D), Duncan Lee ${ }^{1}$, Lucy Neal ${ }^{2}$, Mohit Dalvi $^{3}$, Paul Agnew $^{2}$, Fiona M. O'Connor ${ }^{3}$, \\ Sabyasachi Mukhopadhyay ${ }^{4}$, Sujit Sahu ${ }^{4}$ and Christophe Sarran ${ }^{2}$
}

\begin{abstract}
Background: Estimating the long-term health impact of air pollution in a spatio-temporal ecological study requires representative concentrations of air pollutants to be constructed for each geographical unit and time period. Averaging concentrations in space and time is commonly carried out, but little is known about how robust the estimated health effects are to different aggregation functions. A second under researched question is what impact air pollution is likely to have in the future.

Methods: We conducted a study for England between 2007 and 2011, investigating the relationship between respiratory hospital admissions and different pollutants: nitrogen dioxide $\left(\mathrm{NO}_{2}\right)$; ozone $\left(\mathrm{O}_{3}\right)$; particulate matter, the latter including particles with an aerodynamic diameter less than 2.5 micrometers (PM 2.5$)$, and less than 10 micrometers $\left(\mathrm{PM}_{10}\right)$; and sulphur dioxide $\left(\mathrm{SO}_{2}\right)$. Bayesian Poisson regression models accounting for localised spatio-temporal autocorrelation were used to estimate the relative risks (RRs) of pollution on disease risk, and for each pollutant four representative concentrations were constructed using combinations of spatial and temporal averages and maximums. The estimated RRs were then used to make projections of the numbers of likely respiratory hospital admissions in the 2050s attributable to air pollution, based on emission projections from a number of Representative Concentration Pathways (RCP).
\end{abstract}

Results: $\mathrm{NO}_{2}$ exhibited the largest association with respiratory hospital admissions out of the pollutants considered, with estimated increased risks of between 0.9 and $1.6 \%$ for a one standard deviation increase in concentrations. In the future the projected numbers of respiratory hospital admissions attributable to $\mathrm{NO}_{2}$ in the 2050s are lower than present day rates under 3 Representative Concentration Pathways (RCPs): 2.6, 6.0, and 8.5, which is due to projected reductions in future $\mathrm{NO}_{2}$ emissions and concentrations.

Conclusions: $\mathrm{NO}_{2}$ concentrations exhibit consistent substantial present-day health effects regardless of how a representative concentration is constructed in space and time. Thus as concentrations are predicted to remain above limits set by European Union Legislation until the 2030s in parts of urban England, it will remain a substantial health risk for some time.

Keywords: Air pollution, Present day and future health effects, Spatio-temporal ecological study

*Correspondence: francesca.pannullo@glasgow.ac.uk

'School of Mathematics and Statistics, University of Glasgow, G12 8QW,

Glasgow, UK

Full list of author information is available at the end of the article 


\section{Background}

Air pollution remains a major public health problem. Despite significant improvements in air quality in western Europe and North America over the last 50 years the mortality and morbidity burden remains high. On a global scale the World Health Organisation (WHO) estimated that air pollution was responsible for the premature deaths of 3.7 million people under the age of 60 in 2012 [1]. This global problem is mirrored in the United Kingdom (UK), as it is estimated that 40,000 premature deaths are attributable to air pollution each year [2]. These health problems are likely to remain for some time, as concentrations of air pollutants are predicted to exceed limits set by European Union (EU) legislation beyond 2030 in many urban parts of the UK, especially in England (see for example [3] which relates to nitrogen dioxide). Legally established limits for air pollution do not represent thresholds below which there are no health impacts [4], and it is questionable whether thresholds for health impacts exist.

A wealth of research has been undertaken to quantify the health impact of air pollution across the world, including short-term peak concentrations [5], as well as exposure over the longer term [6]. The latter is the focus of the study described here, and cohort studies are the most popular study design for estimating such chronic effects [7]. However, such studies are expensive and time consuming to conduct, due to the need to recruit a cohort of individuals and repeatedly assess their health status for an extended follow-up period. Therefore, a relatively recent alternative uses freely available population level data relating to non-overlapping areal units for multiple consecutive years, which results in an ecological rather than an individual level study similar to that used to quantify the effects of short-term peak concentrations. Here, the effect of chronic exposure to pollution is estimated from the spatio-temporal contrasts in disease burden and air pollutant concentrations, after adjusting for population demographics and other confounders such as socioeconomic deprivation. Examples of such studies in the UK include [8-12], while non-UK studies include [13-16]. Thus although these studies may be prone to ecological bias, they are used to independently corroborate the evidence from cohort studies.

There have been a number of studies that have investigated the association between air pollutants and respiratory outcomes all over the UK, where the majority of studies focus on London or England as a whole. Most recently, [17] investigated the association between longterm exposure to numerous pollutants and respiratory hospital admissions in England in 2010. They reported increased risks between 8.5 and $9.4 \%$ for a five unit increase in nitrogen dioxide $\left(\mathrm{NO}_{2}\right)$ concentrations, and between 3.2 and $5.5 \%$ for a one unit increase in particles with an aerodynamic diameter less than 2.5 micrometers
$\left(\mathrm{PM}_{2.5}\right)$. [18] also found increased risks in respiratory hospital admissions for $\mathrm{PM}_{2.5}$, but not for $\mathrm{NO}_{2}$. Similarly, [19] observed relationships between $\mathrm{PM}_{10}$ and respiratory mortality, but not for $\mathrm{NO}_{2}$ or carbon monoxide. However, these studies only considered London, but it has been estimated that poor air quality has contributed to 4000 deaths a year. Furthermore, positive relationships have been observed in Scotland, where [12] found a $6.8 \%$ increase in cardio-respiratory mortality for $\mathrm{NO}_{2}$ concentrations between 2006 and 2012 in West Central Scotland, [20] found increases in respiratory hospital admissions ranging between $2.6 \%$ to $4.3 \%$ for $\mathrm{NO}_{2}$ and $\mathrm{PM}_{2.5}$ in Glasgow, and [21] found an overall 6.6\% increase risk for respiratory hospital admissions for Scotland as a whole.

The aim of this paper is to present a new comprehensive study of the long-term effects of air pollution on respiratory hospital admissions in England, UK, between 2007 and 2011. In conducting this study we are motivated by two main epidemiological questions. The first is to investigate the sensitivity of the estimated pollution-health effect to the way in which representative concentrations of air pollutants are constructed at the aggregate level to align with the disease data. Air pollutant concentrations vary continuously in space and time and therefore must be aggregated in both dimensions, which for our study requires a representative concentration for each month for each Local and Unitary Authority (LUA). The average (mean) is typically used to aggregate these data $[8,10]$, but this risks masking periods of peak concentrations that might drive the estimated health effects. Therefore in our analysis we assess the sensitivity of our results to the choice of spatio-temporal aggregation, specifically by comparing averaging against using maximum concentrations in both space and time.

The second epidemiological question we address is what is the population-level health impact that air pollution might have in the future. We attempt to answer this difficult question by first utilising the concentrations of air pollutants and respiratory hospital admissions data between 2007 and 2011 to derive a pollution-health relationship for the present day. We then apply this estimated pollution-health relationship to future projections of climate and air quality, which allows us to make future projections of health burdens in the 2050s. In the next section we present the hospital admission, air pollutant and covariate data utilised in this study, as well as the statistical modelling that was used. The results are then presented followed by a concluding discussion.

\section{Methods}

\section{Study population}

The study region is England, UK (see in Additional file 1: Figure S1), with the isles of Scilly and Wight and the financial district of the City of London removed due to 
their small resident populations and hence very small disease counts. England had a population of around 53 million during the study period, and is partitioned into $K=323$ LUAs. Data are available for these $K$ LUAs at monthly intervals between 2007 and 2011 inclusive, yielding $T=60$ consecutive time periods, making this one of the largest areal unit studies ever conducted. The disease, covariate and pollution data are described below, while additional numerical and graphical summaries are provided in Additional file 1 accompanying this paper.

\section{Disease data}

The disease outcome data were obtained from hospital admissions records from the Health and Social Care Information Centre, where counts of the numbers of emergency hospital admissions (from all ages) in each LUA and month due to respiratory disease (International Classification of Disease 10th revision (ICD-10) codes J00-J99) were created. These counts are denoted by $Y_{k t}$ for the $k$ th LUA and $t$ th month, and a summary of the counts is provided in Additional file 1: Table S1. The expected numbers of admissions $E_{k t}$ for each month and LUA were computed using indirect standardisation, which adjusts for the varying population sizes and demographic structures across the LUA and month combinations. Specifically, $E_{k t}=$ $\sum_{r} N_{k t r} \gamma_{r}$, where $N_{k t r}$ is the number of people in LUA $k$ during month $t$ from age-sex strata $r$ (e.g. males 0-5, etc), while $\gamma_{r}$ is the strata specific disease rate for England.

The exploratory measure of disease risk is the standardised morbidity ratio (SMR) computed as $\mathrm{SMR}_{k t}=Y_{k t} / E_{k t}$, where an SMR of 1.2 corresponds to a $20 \%$ increased risk of disease. The map of the spatial pattern in the average SMR over all $T=60$ months is displayed in panel (a) of Fig. 1. The figure shows the highest SMRs appear around the northern cities in England, such as Leeds, Liverpool and Manchester, while the lowest SMRs appear in more rural areas. Cornwall is an exception to this generalisation, with this rural county exhibiting SMRs comparable to more urban counties. The map also exhibits localised spatial smoothness, where some pairs of neighbouring LUAs have similar values, particularly in south-east England; while other pairs of neighbouring LUAs are very different, for example in the north of England.

The temporal pattern in disease risk is displayed in panel (a) of Fig. 2, which shows a clear seasonal pattern across the years, where higher respiratory risks are present in the winter months due to colder temperatures leading to increases in influenza cases. However, heatwaves (in summer) can also have a negative impact on human health, for example, the 2003 summer heatwave had tens of thousands of attributed deaths [22]. Furthermore, the occurrence of such heatwaves are likely to increase in the future due to the increasing effects of climate change [23]. We therefore adjust for the seasonality in the SMR in two ways. Firstly, we apply a monthly correction factor to $E_{k t}$ to make it seasonal, and secondly we include a measure of temperature as a covariate in the model (see covariate section below). Finally, the seasonally-adjusted SMR does not vary greatly across the 5 -year period as evidenced by the similar distributions for each year (see Fig. 2).

\section{Pollution data}

Concentrations of air pollutants across the UK are measured by the Department for the Environment, Food and Rural Affairs (DEFRA) Automatic Urban and Rural Network (AURN), and in addition to this network local authorities also monitor selected pollutants in key locations where levels are elevated. However, air pollution is often highly spatially heterogeneous, and these measured observations are sparse at the LUA level, with some LUAs having no observations. In order to derive air pollutant concentrations at all points across the UK it is therefore essential to use an air quality model.

Our study uses present-day and future projections of air pollutant concentrations derived from configurations of the UK Met Office's Unified Model (MetUM) [24]. Present-day concentrations for the UK were generated by the Met Office operational air quality forecast model AQUM [25], operated in a hindcast mode. The raw model hourly output data were combined with corresponding hourly surface air pollution measurements by the technique described in [26], to produce improved estimates of pollutant concentrations over the whole UK. The model operates at a spatial resolution of $12 \mathrm{~km}$ and does not explicitly resolve the fine structure of emissions in urban areas. However in view of the spatial and temporal averaging employed in this study, relating pollutant data to health data, this does not present a serious limitation. The future climate and air quality projections were generated by AQUM, nested within regional and global climate-composition models and are fully discussed in (Folberth, GA: Future projections of UK air quality and implications for health, in preperation). Other examples of health studies using modelled pollution data include [10, 27-29].

The air quality model provides hourly concentrations for five pollutants: nitrogen dioxide $\left(\mathrm{NO}_{2}\right)$; ozone $\left(\mathrm{O}_{3}\right)$; particulate matter, the latter including particles with an aerodynamic diameter less than 2.5 micrometers $\left(\mathrm{PM}_{2.5}\right)$, and less than 10 micrometers $\left(\mathrm{PM}_{10}\right)$; and sulphur dioxide $\left(\mathrm{SO}_{2}\right)$. For each pollutant, daily mean and daily maximum concentrations were calculated from the hourly concentrations, which were then both aggregated to the monthly level by taking the arithmetic mean across the days in each month. These monthly concentrations are spatially misaligned to the disease data, since they relate to the $12 \mathrm{~km}$ model grid and not to the irregularly-shaped LUA boundaries. We rectify this by computing both a 


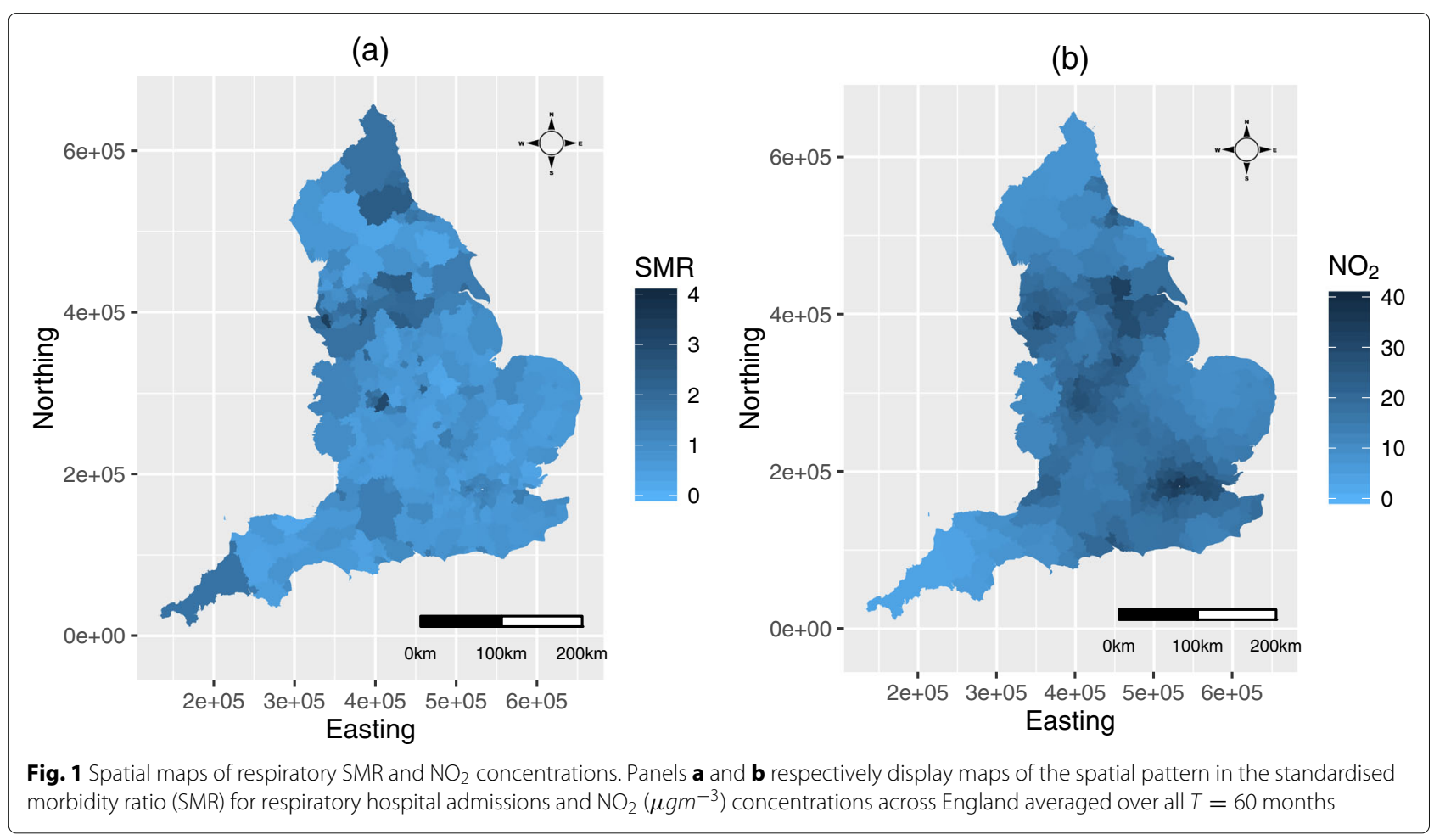

spatial mean (a mean of the grid boxes that fall within the LUA) and a spatial maximum (the maximum of the grid boxes that fall within the LUA) for each LUA and pollutant. Therefore, to assess the robustness of our conclusions to the choice of pollutant aggregation function, the following 4 metrics are computed for each pollutant:

- spatial mean of the temporal mean $\left(\operatorname{mean}_{s} \cdot \operatorname{mean}_{t}\right)$;

- spatial mean of the temporal maximum $\left(\operatorname{mean}_{s} \cdot \max _{t}\right)$;

- spatial maximum of the temporal mean $\left(\max _{s} \cdot \operatorname{mean}_{t}\right)$;

- and spatial maximum of the temporal maximum $\left(\max _{s} \cdot \max _{t}\right)$.

In the above the subscript ${ }_{s}$ denotes spatial and subscript ${ }_{t}$ denotes temporal. The use of these metrics allow us to assess whether peak concentrations over time and space have a stronger association with respiratory disease compared to average concentrations.

Figures and Tables summarising the average concentrations and correlations between the present-day aggregated pollutant metrics are displayed in Additional file 1 accompanying this paper. However, panel (b) in Fig. 1 displays the spatial pattern in the $\mathrm{NO}_{2}$ mean $_{s}$. mean $t$ metric averaged across all time periods, while panel (b) in Fig. 2 displays its temporal pattern via boxplots for each month. The latter highlights a clear seasonal pattern in which $\mathrm{NO}_{2}$ concentrations peak in the colder months, while no trend is seen over the 5 years. The map in Fig. 1 (b) highlights that spatial peaks in $\mathrm{NO}_{2}$ occur around large cities, such as Birmingham.

Future projections of climate and air quality for the 2050 s were produced using the same nested configuration of MetUM, but using greenhouse gas concentrations, aerosol and aerosol precursor emissions, and tropospheric ozone $\left(\mathrm{O}_{3}\right)$ precursor emissions for the 2050s following three of the Intergovernmental Panel on Climate Change (IPCC) fifth assessment report's (AR5) Representative Concentration Pathways (RCPs): RCP2.6 [30], RCP6.0 [31], and RCP8.5 [32]. Corresponding sea surface temperatures (SSTs) and sea ice (SI) conditions were taken from simulations of the HadGEM2-ES model [33] run with the same climate forcings and air quality emissions [34]. While these pathways capture the possible range of future climate in the 2050s, they uniformly assume the global implementation of air quality policies, with aggressive reduction of air pollutant emissions in the 2050s relative to the present-day, with the exception of methane $\left(\mathrm{CH}_{4}\right)$ in $\mathrm{RCP} 8.5$, an important precursor of tropospheric $\mathrm{O}_{3}$. As a result, they do not capture the full range of possible future air quality [35]. Future projections were produced for all aforementioned pollutants on the same $12 \mathrm{~km}$ square grid under each of the three RCPs. As with the present day concentrations, daily means and daily maximum concentrations were computed from the hourly data, which were then aggregated to the monthly and LUA level using the same metrics as the present-day pollution data. These data are again summarised in Additional file 1. 


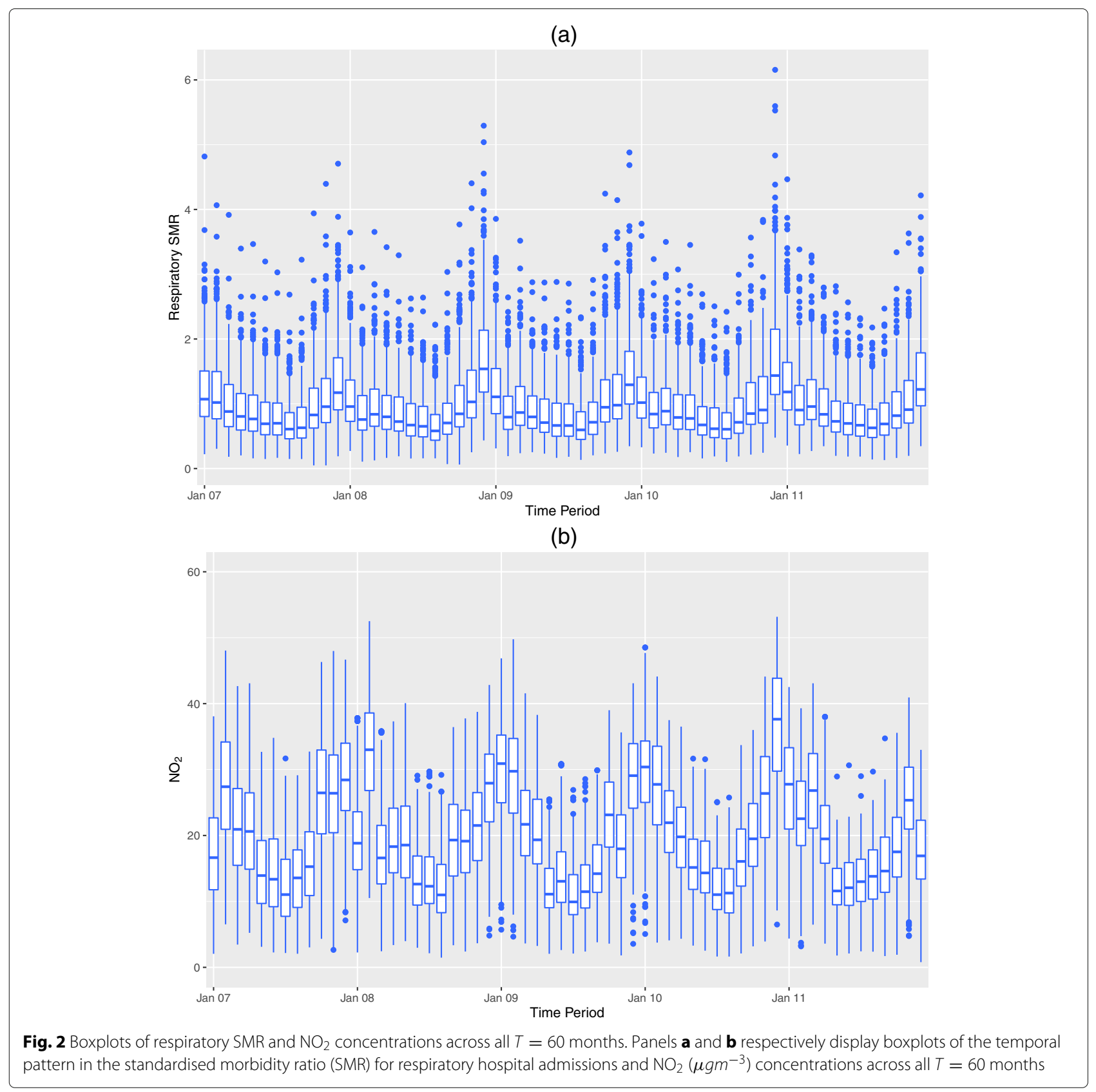

\section{Covariate data}

One of the key confounding factors in ecological pollution-health studies is socio-economic deprivation [36], since populations with higher levels of socioeconomic deprivation are more likely to undertake risky behaviours such as smoking and poor diet, and thus have poorer respiratory health overall. Socio-economic deprivation is a combination of multiple factors which makes it difficult to measure, and so we use two proxy measures, namely: the percentage of the working age population that is in receipt of Job Seekers Allowance (JSA) (a benefit paid to working age people out of work), and the median property price (MPP). JSA and MPP are available for all LUAs across England, but only at the annual temporal resolution, and the distributions are summarised in Additional file 1: Table S1 accompanying this paper. It was not possible to assess whether smoking was a confounder in our analyses as information on smoking was not available at the LUA level. Smoking should be highly correlated with deprivation, which we have adjusted for. This was demonstrated in the paper by [18] who showed that in London at the borough level smoking prevalence was linearly related to JSA (Pearson's correlation coefficient of 0.67) suggesting that deprivation variables, such as JSA, 
can serve as a proxy variable for smoking. In addition, temperature is well known to impact respiratory disease [37], with very cold and very warm temperatures leading to increased admissions. For this study we use the average modelled temperature in each LUA and month, and again these data are summarised in Additional file 1: Table S1.

\section{Statistical analysis}

Poisson log-linear models are typically used to model these data, where the spatio-temporal pattern in disease risk is modelled by known covariates and spatiotemporally autocorrelated random effects $[10,18]$. The latter are included in the model to account for residual spatio-temporal autocorrelation, which is autocorrelation remaining in the disease data after adjusting for known covariates. This autocorrelation is caused by many factors, such as unmeasured confounding, neighbourhood effects (where the behaviour of individuals is influenced by the behaviour of neighbouring individuals), grouping effects (where individuals choose to be close to similar individuals), and the fact that successive observations in the same unit relate to largely the same susceptible population. The presence of this residual autocorrelation violates the assumption of independence made in simple regression models, requiring the inclusion of autocorrelated random effects in the model.

Typically, a Gaussian Markov Random Field (GMRF) model is specified for these random effects [8-10, 13-16, $18,20]$, and inference for the model is set in a Bayesian setting using Markov chain Monte Carlo (MCMC) simulation. The model used here was proposed by [38], and has the general form:

$$
\begin{aligned}
Y_{k t} \mid E_{k t}, R_{k t} & \sim \operatorname{Poisson}\left(E_{k t} R_{k t}\right), \\
\ln \left(R_{k t}\right) & =\mathbf{x}_{k t}^{\top} \boldsymbol{\beta}+\phi_{k t},
\end{aligned}
$$

where $R_{k t}$ denotes the overall disease risk in the $k$ th LUA and $t$ th month relative to the expected disease count $E_{k t}$. The vector of known covariates (air pollutant, socioeconomic deprivation and temperature) is denoted by $\mathbf{x}_{k t}$, while the corresponding regression parameters are denoted by $\boldsymbol{\beta}$. The spatio-temporal random effect for area $k$ and month $t$ is denoted by $\phi_{k t}$, while the vector for all LUA for month $t$ is denoted by $\phi_{t}=\left(\phi_{1 t}, \ldots, \phi_{K t}\right)$. The GMRF prior used here models these effects as:

$$
\begin{aligned}
\boldsymbol{\phi}_{t} \mid \boldsymbol{\phi}_{t-1} & \sim \mathrm{N}\left(\gamma \boldsymbol{\phi}_{t-1}, \tau^{2} \mathbf{Q}(\mathbf{W}, \rho)^{-1}\right), t=2, \ldots, T, \\
\boldsymbol{\phi}_{1} & \sim \mathrm{N}\left(\mathbf{0}, \tau^{2} \mathbf{Q}(\mathbf{W}, \rho)^{-1}\right),
\end{aligned}
$$

which is a multivariate first order autoregressive process. Temporal autocorrelation is modelled via the mean $\gamma \boldsymbol{\phi}_{t-1}$, where $\gamma$ is the temporal autocorrelation parameter, with a value of zero corresponding to independence while a value of one corresponds to strong temporal autocorrelation. The spatial structure in the data is represented by $\mathbf{W}$, a binary $K \times K$ spatial adjacency matrix, where $w_{k j}=1$ if the $(k, j)$ th LUAs share a common border and is zero otherwise (diagonal elements $w_{k k}=0$ ). Thus, spatial autocorrelation in the data is modelled by the singular precision matrix

$$
\mathbf{Q}(\mathbf{W}, \rho)=\rho[\operatorname{diag}(\mathbf{W} \mathbf{1})-\mathbf{W}]+(1-\rho) \mathbf{I},
$$

where $\mathbf{1}$ is a $K \times 1$ unit vector and $\mathbf{I}$ is the $K \times K$ identity matrix. This precision matrix corresponds to the Gaussian Markov Random Field prior proposed by [39], and is commonly used for spatial areal unit modelling applications. Here $\rho$ is the spatial dependence parameter, with a value of zero corresponding to independence while a value of one corresponds to strong spatial autocorrelation. However, this model captures globally smooth spatial autocorrelation, which as shown in Additional file 1: Figure S4 is not suitable for our data. The figure shows a spatial map of the residuals on the log-scale (averaged over time) from a simplified model including only the covariates (the random effects are removed), from which localised spatial smoothness that is present between some pairs of neighbouring areas but absent between others is clearly visible.

Thus here we treat the elements of $\mathbf{W}$ corresponding to pairs of spatially adjacent LUA as random quantities to be estimated, rather than being fixed at one. If the corresponding $w_{k j}$ element is estimated as close to one then strong spatial autocorrelation is assumed between $\left(\phi_{k t}, \phi_{j t}\right)$ for all time periods $t$, while if it is estimated as close to zero then the random effects are modelled as conditionally independent. Full details of this model are given by [38], and the model can be implemented using the CARBayesST software in the statistical software $R$.

We quantify the impact of future air pollution on respiratory hospitalisation rates by estimating the change in the numbers of hospital admissions that would occur if the present-day air pollutant concentrations from 2007 to 2011 were replaced by the future projections. The first step to achieving this is to compute the relative risk of hospitalisation comparing the current and future air pollutant concentrations. That is for area $k$ and year $t$ (e.g., comparing January 2007 against January 2050, February 2008 against February 2051, etc) we have

$$
\begin{aligned}
\mathrm{RR}_{k t} & =\frac{\text { Expected number of admissions given current levels }}{\text { Expected number of admissions given projected levels }} \\
& =\frac{E_{k t} \exp \left(\mathbf{x}_{k t}^{\top} \hat{\boldsymbol{\beta}}+\phi_{k t}\right)}{E_{k t} \exp \left(\mathbf{z}_{k t}^{\top} \hat{\boldsymbol{\beta}}+\phi_{k t}\right)} \\
& =\exp \left(\left[z_{k t}^{(p)}-x_{k t}^{(p)}\right] \hat{\beta}^{(p)}\right) .
\end{aligned}
$$

In the above equation $\left(\mathbf{x}_{k t}, \mathbf{z}_{k t}\right)$ respectively denote the vector of covariates for the present-day and future, and only differ in their pollutant concentrations $\left(x_{k t}^{(p)}, z_{k t}^{(p)}\right)$. 
The remaining socio-economic deprivation and temperature covariates relate to the present day values. Finally, $\hat{\beta}^{(p)}$ is the estimated relationship between air pollution and disease risk from the present-day analysis. Then, based on the present-day population, if pollution over the 5-year period changed from the 2007-2011 levels to the 2050 s levels then the estimated annual average number of increased / reduced admissions over all $K=323$ LUA would be:

$$
\hat{n}=\frac{1}{5} \sum_{k=1}^{323} \sum_{t=1}^{60} R R_{k t} Y_{k t}-Y_{k t} .
$$

The first term $R R_{k t} Y_{k t}$ is the estimated number of respiratory hospital admissions if the present-day pollution levels were replaced by the future projections, while the second term is obviously the number of admissions resulting from the present-day air pollutant concentrations. For example, if the concentrations had not changed, that is if $z_{k t}^{(p)}=x_{k t}^{(p)}$ then the relative risk $R R_{k t}=1$ and $\hat{n}=0$ as would be expected.

\section{Results}

The aforementioned statistical model is fitted in a Bayesian setting via MCMC simulation using the CARBayesST package for $R$ available from https://cran. r-project.org. All the results presented are based on 10,000 MCMC samples, that were generated by running a Markov chain for 120,000 samples of which the first 20,000 were discarded as the burn-in period (by which point convergence was assessed to have been reached) and the remaining 100,000 were thinned by a factor of 10 , by retaining every 10 th data point, to reduce their autocorrelation.

Each aggregation metric for each pollutant was included in a separate disease model due to the collinearity between the different pollutants and between the different aggregation metrics for the same pollutant. The covariates in each model included a single measure of pollution, temperature and socio-economic deprivation, the latter including the percentage of the working age population in receipt of job seekers allowance and the median property price in each LUA.

Fitting the models showed there was strong spatiotemporal autocorrelation present in the disease data after adjusting for the known covariates, since the estimated spatial and temporal autocorrelation parameters were $(\hat{\rho}=0.98, \hat{\gamma}=0.99)$. Values of zero for these parameters correspond to independence, while values close to one correspond to strong autocorrelation.

The estimated relative risk for temperature for a $4.682{ }^{\circ} \mathrm{C}$ (equating to one standard deviation) increase ranged between 0.867 and 0.922 depending on the pollution metric included in the model, which is around a
$10 \%$ reduction in risk for a $4.682{ }^{\circ} \mathrm{C}$ increase. These estimated effects were significant at the 5\% level, as the $95 \%$ credible intervals (the Bayesian equivalent of frequentist confidence intervals) were wholly below the null risk of one. This negative relationship with the risk of respiratory hospital admissions is somewhat expected, since colder temperatures are known to result in greater numbers of hospital admissions. However, the possibility of a non-linear relationship was considered for temperature to account for the potential harmful effects of heatwaves, but exploratory analyses suggested a linear relationship was sufficient for the data.

Both the socio-economic deprivation covariates JSA and MPP were allowed to exhibit non-linear relationships with disease risk, which was achieved by modelling their effects with natural cubic splines with 3 degrees of freedom. The resulting relationships are displayed in Fig. 3, where the top plot refers to MPP, and the bottom plot refers to JSA. In both cases the tick marks on the $\mathrm{x}$ axis relate to the values of each covariate in the data set. The figure shows that both covariates suggest that disease risk increases as socio-deprivation increases, which relates to a decrease in MPP and an increase in JSA. The apparent reduction in risk as JSA increases from 20 to $40 \%$ is likely to be spurious, as it is based on few data points (see the tick marks on the $\mathrm{x}$ axis) and a horizontal line (representing no change) fits between the wide $95 \%$ credible intervals. Finally, both covariates show strong evidence of non-linear behaviour on disease risk, as straight lines cannot be drawn to stay within the $95 \%$ credible intervals across the entire range of the covariates.

The estimated relationships between each pollutant and aggregation metric and respiratory hospital admissions are displayed in Table 1, where all results are presented as relative risks for a one standard deviation increase in each metrics value. These standard deviation increases are presented in the table caption. The table shows that $\mathrm{NO}_{2}$ associated with respiratory hospital admissions across all aggregation metrics, since the relative risks are all positive and their $95 \%$ credible intervals are wholly above the null risk of one. The aggregation metric with the highest relative risk of 1.016 was for the mean $_{s}$. mean $_{t}$ metric, indicating that for around a $10 \mathrm{\mu gm}^{-3}$ increase in $\mathrm{NO}_{2}$ the risk of respiratory hospital admissions increases by $1.6 \%$. The magnitude of the differences in the estimated effects across the four aggregation metrics is small in absolute size, as the estimates range between 1.009 and 1.016 , suggesting that these results are relatively robust to the choice of a representative aggregated measure of pollution.

$\mathrm{PM}_{10}$ and $\mathrm{PM}_{2.5}$ are estimated to have marginal impacts on increased respiratory hospitalisation, since their relative risks are all above one for each aggregation metric. $\mathrm{PM}_{2.5}$ exhibits slightly higher estimated risks compared to 


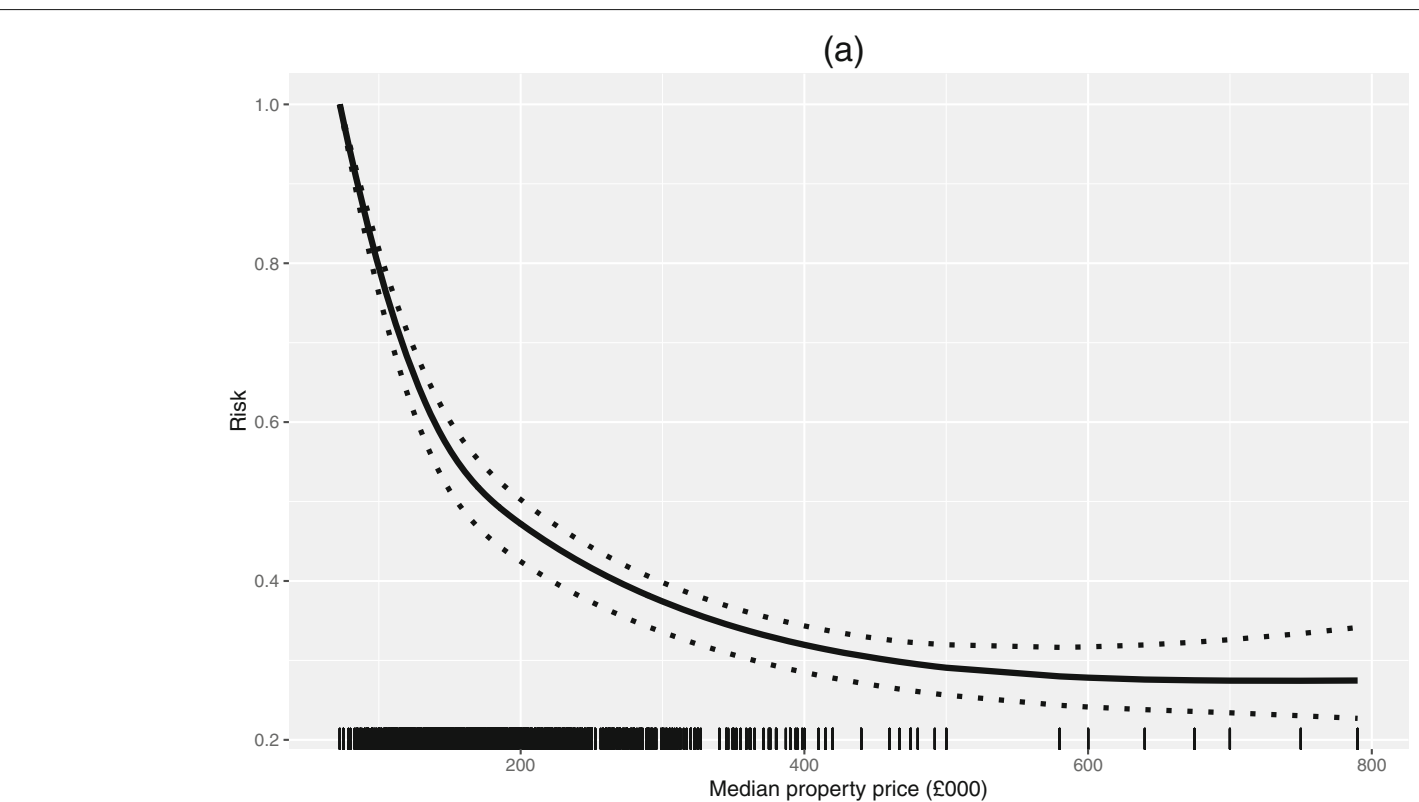

(b)

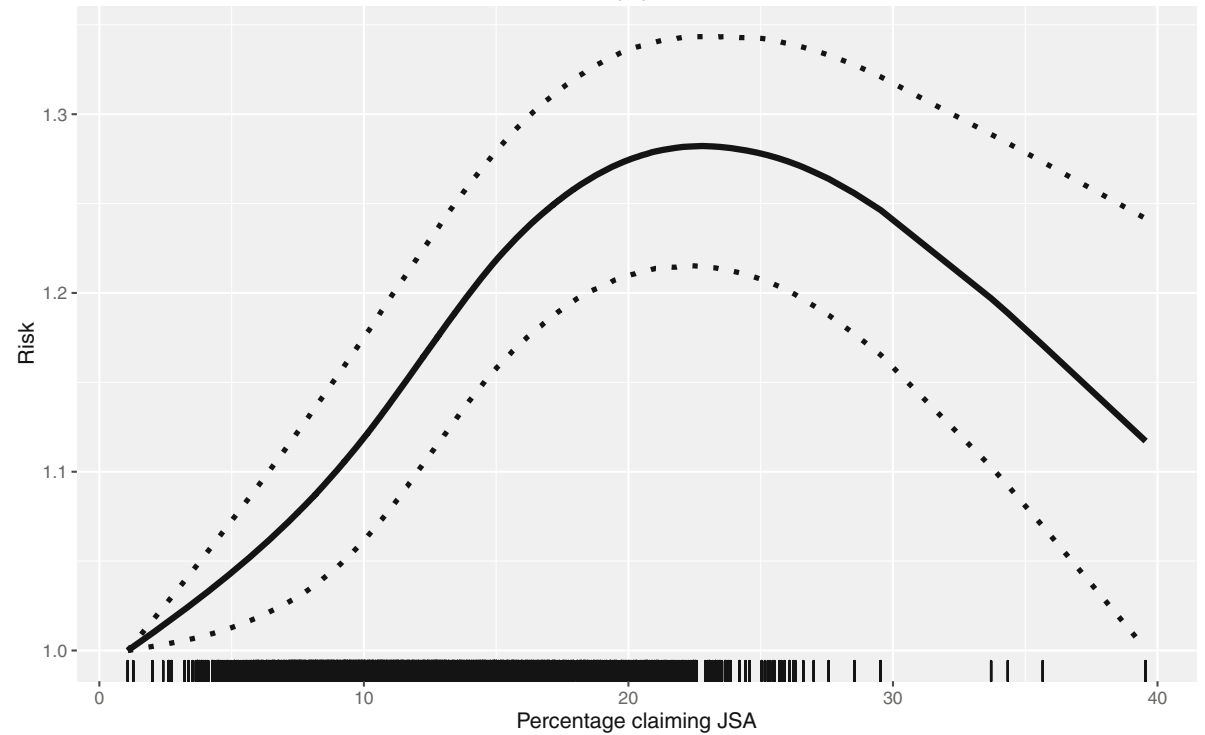

Fig. 3 Estimated risks between MPP and JSA against the risk of respiratory admission. Panels $\mathbf{a}$ and $\mathbf{b}$ respectively display the estimated non-linear relationships between the risk of respiratory hospital admission and the two deprivation covariates, namely median property price and job seekers allowance claimants. The solid curve denotes the estimated relationship, and the dashed lines denote the $95 \%$ credible intervals. The tick marks on the $x$ axis represent the locations of the data points in covariate space

$\mathrm{PM}_{10}$. However, for both pollutants the estimated effect sizes are closer to one compared with $\mathrm{NO}_{2}$ and are not substantial at the $5 \%$ level, the latter being because the $95 \%$ credible intervals include the null risk of one.

$\mathrm{SO}_{2}$ exhibits no relationship with respiratory hospital admission risk for any of the aggregation metrics, with all estimated relative risks being equal to one to two decimal places. In contrast, $\mathrm{O}_{3}$ showed a negative association with the risk of respiratory hospital admission, that is increasing concentrations being estimated to reduce respiratory admissions. However, this is likely due to confounding from the study design, because $\mathrm{O}_{3}$ has a negative correlation with $\mathrm{NO}_{2}$ (-0.68 for the mean . mean $_{t}$ metric). This negative correlation means that as $\mathrm{NO}_{2}$ has a positive effect then a negatively correlated pollutant such as $\mathrm{O}_{3}$ will likely have an estimated effect of the opposite sign.

Sensitivity analyses were performed investigating the effect of two-pollutant models in order to take into account the contemporaneous effects of two pollutants on the risk of respiratory hospital admissions. The correlation between the pollutants were relatively high, 
Table 1 Posterior medians and 95\% credible intervals (in brackets) for the estimated relationship between each pollutant and aggregation metric and respiratory hospitalisation

\begin{tabular}{lllll}
\hline Pollutant & mean $_{s} \cdot$ mean $_{t}$ & mean $_{s} \cdot \mathrm{max}_{t}$ & max $_{s} \cdot \mathrm{mean}_{t}$ & max $_{s} \cdot \mathrm{max}_{t}$ \\
\hline $\mathrm{NO}_{2}$ & $1.016(1.008,1.028)$ & $1.014(1.009,1.011)$ & $1.009(1.000,1.016)$ & $1.011(1.004,1.016)$ \\
$\mathrm{O}_{3}$ & $0.985(0.973,0.995)$ & $0.992(0.980,1.002)$ & $0.986(0.974,0.997)$ & $0.998(0.986,1.008)$ \\
$\mathrm{PM}_{10}$ & $1.008(0.999,1.020)$ & $1.004(0.994,1.012)$ & $1.006(0.994,1.022)$ & $1.005(0.993,1.014)$ \\
$\mathrm{PM}_{2.5}$ & $1.008(0.997,1.024)$ & $1.006(0.996,1.013)$ & $1.010(0.999,1.020)$ & $1.004(0.997,1.014)$ \\
$\mathrm{SO}_{2}$ & $1.000(0.995,1.004)$ & $0.999(0.995,1.005)$ & $0.999(0.994,1.004)$ & $0.999(0.995,1.005)$ \\
\hline
\end{tabular}

Results are presented as relative risks for a 1 standard deviation increase in each pollutants value (measured in $\mu \mathrm{gm}^{-3}$ ) which are (in the order of the aggregation metrics below): $\mathrm{NO}_{2}(9.56,13.63,9.6,13.51), \mathrm{O}_{3}(13.55,15.8,13.79,15.97), \mathrm{PM}_{10}(5.1,7.47,5.17,7.52), \mathrm{PM}_{2.5}(4.22,6.05,4.22,6.06), \mathrm{SO}_{2}(1.38,3.48,1.77,3.83)$

however the correlation between $\mathrm{NO}_{2}$ and $\mathrm{PM}_{2.5}$ was only 0.540 , and -0.68 between $\mathrm{NO}_{2}$ and $\mathrm{O}_{3}$. The Committee on the Medical Effects of Air Pollutants [40] suggest that associations with $\mathrm{O}_{3}$ could be masked when there is no adjustment for negatively correlated pollutants, such as $\mathrm{NO}_{2}$. Utilising the aforementioned methodology two extra models were considered looking at the joint effects of $\mathrm{NO}_{2}$ with $\mathrm{PM}_{2.5}$, and $\mathrm{NO}_{2}$ with $\mathrm{O}_{3}$ for the mean . mean metric. The relative risks for the $\mathrm{NO}_{2}-\mathrm{PM}_{2.5}$ model are as follows: $1.014(1.008,1.028)$ for $\mathrm{NO}_{2}$, and $1.003(0.990$, 1.015) for $\mathrm{PM}_{2.5}$. The relative risks for the $\mathrm{NO}_{2}-\mathrm{O}_{3}$ model are as follows: $1.015(1.002,1.029)$ for $\mathrm{NO}_{2}$, and 1.001 $(0.980,1.015)$ for $\mathrm{O}_{3}$. These effects show slight attenuation for $\mathrm{NO}_{2}$ and $\mathrm{PM}_{2.5}$ compared to the single-pollutant only models (see Table 1 ) highlighting the robustness of these effects when only considered on their own. For $\mathrm{O}_{3}$, the effect changes from slightly negative (with a credible interval close to the null risk of one) to no association, while $\mathrm{NO}_{2}$ only shows slightly attenuation. Again, this highlights the robustness of our findings when only singlepollutant models are considered. In addition, it has been demonstrated that hot and cold temperatures can affect the respiratory system, therefore monthly minimum and maximum temperatures were calculated and included in a model with the $\mathrm{NO}_{2}$ mean $_{\text {s. }}$ mean $_{t}$ metric. The correlation between average and minimum temperature was 0.973 , and 0.948 between average and maximum temperature. The relative risks for $\mathrm{NO}_{2}$ increased to 1.018 (1.012, $1.028)$ and $1.017(1.006,1.026)$ for maximum and minimum temperature respectively, compared to a relative risk of $1.016(1.008,1.028)$ when average temperature was used. These results suggest that due to the high correlation between the temperature metrics the relative risk for $\mathrm{NO}_{2}$ is consistent. The relative risk for temperature is consistent across the three measures, ranging from 0.892 $(0.858,0.919)$ for average temperature, $0.962(0.921,0.979)$ for minimum temperature, and $0.989(0.965,0.999)$ for maximum temperature. However, the effects for temperature are slightly attenuated when minimum and maximum values are used. Therefore, in our study the effect of temperature on respiratory hospital admissions is consistent across the three measures. In addition to the sensitivity analyses conducted above, another model was performed that investigated the joint effect of $\mathrm{PM}_{10}$ and $\mathrm{O}_{3}$ since the correlation between these two pollutants was extremely low at -0.083 . For the mean $_{s} \cdot$ mean $_{t}$ metric the relative risk for $\mathrm{PM}_{10}$ was $1.001(0.987,1.011)$, and $0.985(0.975,1.000)$ for $\mathrm{O}_{3}$. The effect for $\mathrm{O}_{3}$ did not change compared to the single pollutant model, and there was slight attenuation for the $\mathrm{PM}_{10}$-health effect. Likewise, these results emphasise the robustness of the effects when only considered in single pollutant models.

In the above results $\mathrm{NO}_{2}$ exhibited the strongest effect on respiratory hospital admissions since its 95\% credible intervals did not contain the null risk of one, and is thus chosen to estimate the impact of future climate and air quality on the future risk of hospitalisation due to respiratory disease. In this analysis the results for the mean $_{s}$. ax $_{t}$ metric are presented in Table 2, while the results for the other metrics are similar and are discussed in the supplementary material. The method outlined in the previous section is used, whereby we first compute the relative risk using (4), then estimate the yearly average number of attributable respiratory hospital admissions using (5). In RCPs 2.6, 6.0, and 8.5, the number of respiratory hospital admissions in England are projected to decrease in the 2050 s by $10,478,8,659$, and 14,661 , respectively. The average number of present-day respiratory hospital admissions per year is 613,052 across England, thus these decreases relate to RCP2.6 - 1.7\%, RCP6.0 $1.4 \%$, and RCP8.5 - 2.4\% reductions compared with the

Table 2 Projected $\mathrm{NO}_{x}$ emission totals under the three RCPs and the percentage of the present-day (2007-11) emission totals for UK-only emissions that each one relates to

\begin{tabular}{llll}
\hline RCP & $\begin{array}{l}\text { Total emissions } \\
(\mathrm{kg} / \mathrm{s})\end{array}$ & \% of present-day & $\begin{array}{l}\text { Number of reduced } \\
\text { admissions } \hat{n}\end{array}$ \\
\hline 2.6 & 21.46 & 69.23 & $10,478(15,435,4,367)$ \\
6.0 & 23.25 & 75.02 & $8,659(12,740,3,615)$ \\
8.5 & 13.22 & 42.66 & $14,661(21,546,6,128)$ \\
\hline
\end{tabular}

The total present-day $\mathrm{NO}_{x}$ emissions are $30.99 \mathrm{~kg} / \mathrm{s}$. Also presented are the estimated reductions in respiratory admissions per year and $95 \%$ credible intervals in brackets 
current admissions rates. Thus the estimated numbers of admissions reduce across all three pathways, with climate scenario RCP8.5 producing the highest reduction and RCP6.0 producing the lowest. These projected decreases in respiratory admissions are driven by projected decreases in $\mathrm{NO}_{2}$ concentrations across all 3 RCPs. It is important to note that a RCP which has a higher mean temperature increase does not necessarily imply higher air pollutant concentrations.

To interpret our results one must consider how the nitrogen oxide $\left(\mathrm{NO}_{x}=\mathrm{NO}\right.$ and $\left.\mathrm{NO}_{2}\right)$ emissions vary between the three RCPs. The average projected $\mathrm{NO}_{x}$ emissions (kg per second) for the UK for each RCP for the 2050s is displayed in Table 2, which also displays the emissions as a percentage of present day values. The table displays reductions of between 42.66 and $75.02 \%$ under each RCP compared to present-day $\mathrm{NO}_{x}$ emission totals. Therefore, it is clear that $\mathrm{NO}_{x}$ emissions significantly reduce under the future climate projections. This is the main driver for the reductions in projected hospital admissions due to respiratory disease in all RCPs. These projected reductions in admissions are also displayed in Table 2, and range between 8659 and 14,661 per year. RCP6.0 has the lowest reduction in projected respiratory hospital admissions compared to the other two scenarios, consistent with the fact that it also has the smallest reduction in $\mathrm{NO}_{x}$ emissions. Variations also arise amongst the different RCPs due to emissions of other pollutants (for example, $\mathrm{SO}_{2}$ has the highest emissions in RCP6.0), non-linear chemistry feedbacks in the atmosphere, and the differing meteorology, which in turn all affect air concentrations of $\mathrm{NO}_{2}$.

Figure 4 displays the spatial distribution of the projected yearly average reductions in respiratory hospitalisations by LUA from all 3 RCPs across England. In the figure the minus numbers denote the size of the projected reductions in hospital admissions if the current day mean $_{s}$. max $_{t}$ $\mathrm{NO}_{2}$ concentrations were replaced by the projections under RCPs 2.6, 6.0 and 8.5. The maps indicate that in all $3 \mathrm{RCPs}$ the highest reductions in $\mathrm{NO}_{2}$ concentrations and hence respiratory admissions occur in the urban cities of London (south east), Birmingham (central) and Liverpool, Manchester and Leeds (north). In contrast, there are smaller changes in the more rural areas.

\section{Discussion}

This paper has presented a new comprehensive study of the long-term effects of air pollution on respiratory hospitalisation rates in England between 2007 and 2011, as well as estimating the future impact of air pollution for the 2050s. The study is at the LUA and monthly resolution, and with 19,380 spatio-temporal observations is one of the largest spatio-temporal areal unit studies ever conducted. It was also straightforward to implement, making use of routinely available aggregated respiratory hospital admissions records and modelled regional air pollutant concentrations. Both these data sets are available in Additional file 2 accompanying this paper, and the sophisticated spatio-temporal models used to estimate the pollution-health effects are freely available via the $R$ package CARBayesST. The two key aims of this study were to: (i) examine the sensitivity of the estimated pollution-health effect to the approach taken to computing a representative measure of air pollutant concentrations for each LUA and month; and (ii) use the estimated pollution-health relationship and future projections of concentrations to estimate the potential health burden from air pollution in the future.

In regard to aim (i), a representative LUA and monthly air pollutant concentration is typically computed by averaging concentrations over space and time. In this paper we compared four different aggregation metrics based on computing averages and maximums in space and time, and our main finding is that the results showed very little sensitivity to the choice of metric. The consistency of the results across aggregation metrics is a reassuring finding, and suggests, for this study at least, that the choice of aggregation function did not impact the substantive conclusions. However, it is slightly at odds with the results from [41] in Scotland, who found that the spatial maximum $\mathrm{NO}_{2}$ concentrations produced significant health effects, while the spatial mean had no such relationship. Therefore in future it would be interesting to conduct similar sensitivity analyses in studies at different locations to assess whether the robustness observed here holds more widely.

For all aggregation metrics $\mathrm{NO}_{2}$ exhibited clear associations with respiratory hospital admissions since the 95\% credible intervals were wholly above the null risk of one, with estimated increased risks of between 0.9 and $1.6 \%$ for a one standard deviation increase in concentrations. This result suggests that, as $\mathrm{NO}_{2}$ concentrations are predicted to exceed EU legislation in parts of urban England until at least the 2030s [3], $\mathrm{NO}_{2}$ will be an ongoing health concern for some time. In contrast, the two particulate matter metrics exhibited much smaller (nonsignificant) but still positive associations with respiratory hospital admissions, while $\mathrm{SO}_{2}$ exhibited no association at all. Furthermore, the pollutants were included separately in the models due to their relatively high pairwise correlations. It has been shown that combining $\mathrm{NO}_{2}$ and $\mathrm{O}_{3}$ into a single metric produces pollution-health associations of a greater magnitude compared to conducting two single-pollutant analyses [42]. However, in our sensitivity analysis we ran a model with both $\mathrm{NO}_{2}$ and $\mathrm{O}_{3}$ as covariates, where the effect sizes were only slightly attenuated. Therefore, future work could investigate this relationship within this spatial ecological setting to see whether similar 


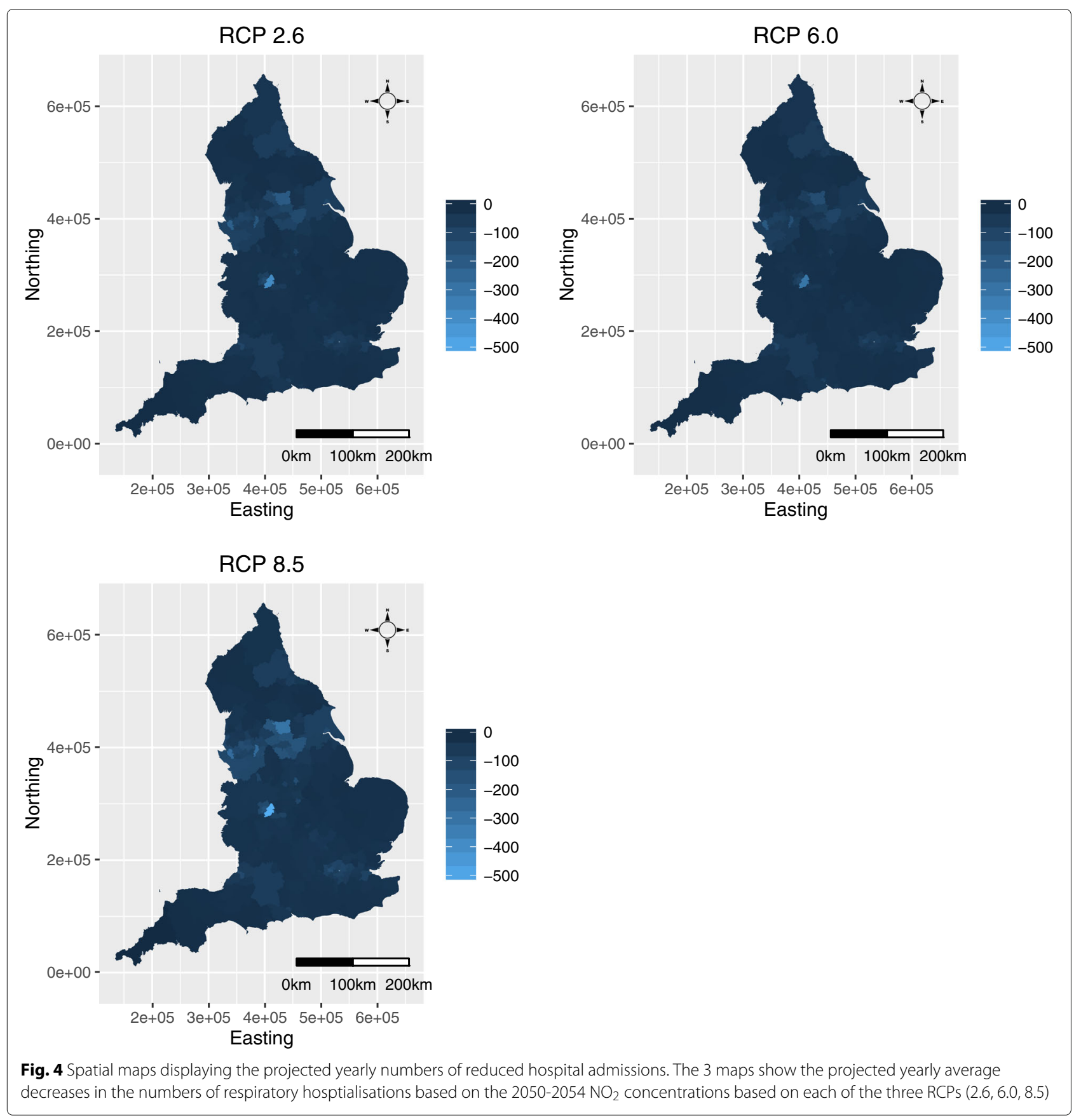

results are found when combing into one $\mathrm{NO}_{2}-\mathrm{O}_{3}$ metric. The relationships observed here are in line with previous ecological studies conducted in England where [17] found stronger effects on respiratory hospital admissions for $\mathrm{NO}_{2}$ compared to $\mathrm{PM}_{2.5}$ and $\mathrm{PM}_{10}$. They estimated stronger effects for $\mathrm{NO}_{2}$ of between 8.5 and $9.4 \%$ compared to our study where the effects ranged between 0.9 and $1.6 \%$. However, this was a purely spatial study conducted in 2010 and only average temporal and spatial aggregated metrics were considered. Information on smoking prevalence was not available, however the same deprivation measures were used and are thus sufficient in the control for smoking. [18] conducted a spatio-temporal study in London where higher relative risks in respiratory hospital admissions were observed for $\mathrm{PM}_{2.5}$ compared to our study ( $1.8 \%$ versus $0.8 \%)$. In contrast, they found no association for $\mathrm{NO}_{2}$ concentrations since its credible interval contained the null risk of one, but the estimated relative risk of 1.013 is in line with our observed relative risk of 1.016 for $\mathrm{NO}_{2}$. Again, no information on 
smoking was available at their chosen area level, however the authors state that their deprivation measures were sufficient at acting as a proxy variable for smoking. Stronger effects were observed for respiratory mortality in the study conducted by [9] across electoral wards in Great Britain, where concentrations of black smoke produced an excess risk of $3.6 \%$ (2.6\%, 4.5\%). However, only wards that contained a monitoring site were included, meaning many wards and thus important information had to be discarded. This highlights the need for spatially complete air pollutant data so that all available information can be utilised. Finally, our results also align with studies conducted in Scotland, where stronger risks are observed for $\mathrm{NO}_{2}$ compared to other pollutants $[10,12,20,41,43]$. Furthermore, [41] computed the spatial maximum $\mathrm{NO}_{2}$ concentrations as well as the typical average aggregation metric, where they found increased associations with the spatial maximum rather than with the spatial mean. Conversely, we found slightly stronger effects when the spatial mean was used rather than the spatial maximum, therefore more work is needed in order to understand this phenomenon further.

The results addressing the second aim of this study suggest that in the future the impact of $\mathrm{NO}_{2}$ concentration on respiratory hospital admissions will fall, with estimated decreases in admissions of between $1.4 \%$ and $2.4 \%$ depending on which of the 3 RCPs used here are considered. However, the RCPs considered all assume a reduction in $\mathrm{NO}_{x}$ emissions across the $\mathrm{UK}$, which is a partial driver of projected falls in $\mathrm{NO}_{2}$ concentrations. Therefore it would be interesting in future work to compare results from the new range of climate and air quality scenarios being developed for the next IPCC assessment [44], which will consider different air quality policies for a given climate change scenario.

From a methodological perspective, the statistical models assumed in this paper, and in almost all the existing literature, assume the aggregated pollutant concentration for each areal unit and time period is fixed and known precisely, whereas in fact it is an error prone estimate. Therefore the uncertainty in its value should be accounted for when estimating its health effects. One approach to achieving this was proposed by [45], who created an exposure distribution for each areal unit and time period, and averaged the estimated pollution-health effects over this exposure distribution. However, a number of approaches are possible for accounting for this exposure uncertainty, and a rigorous comparison of the different approaches is much needed.

\section{Conclusions}

In conclusion, $\mathrm{NO}_{2}$ concentrations exhibit the greatest association with respiratory hospital admissions in our study. This result is consistent across the different aggregation metrics used in the analysis. In view of the continuing, relatively high concentrations predicted for the next 15 or so years [3], this pollutant is likely to remain a serious health risk for some time. In the longer-term, if pollutant concentrations fall by the 2050 s as projected by the RCPs, then the health burden of $\mathrm{NO}_{2}$ will likely decrease on this timescale. The present study can help inform air quality emission control policies in order to benefit the population as a whole, as it is clear that air pollution will remain a major public health problem for some considerable time to come.

\section{Additional files}

Additional file 1: Supplementary data analysis. This file contains additional data description, numerical and graphical summaries, and analysis not presented in the main paper. (PDF $1010 \mathrm{~kb}$ )

Additional file 2: Study data. This is a . zip file containing the data used in the study. The file also contains a read-me document summarising the content of the file. (ZIP $5070 \mathrm{~kb}$ )

\section{Abbreviations}

AQUM: Air quality forecasting and modelling in the Unified Model; AURN: Automatic Urban and Rural Network; DEFRA: Department for the Environment, Food and Rural Affairs; EU: European Union; GMRF: Gaussian Markov Random Field; ICD-10: International Classification of Disease 10th Revision; IPCC:

Intergovernmental Panel on Climate Change; JSA: Job Seekers Allowance LUA: Local and Unitary Authority; $\max _{s}$. $\max _{t}$ : spatial max of the temporal max; max $_{s}$. meant: spatial max of the temporal mean; MCMC: Markov chain Monte Carlo mean $_{s}$. max $_{t}$ : spatial mean of the temporal max; mean . mean $_{t}$ : spatial mean of the temporal mean; MetUM: Met Office Unified Model; MPP: Median Property Price; $\mathrm{NO}_{2}$ : Nitrogen dioxide; $\mathrm{NO}_{x}$ : Nitrogen Oxide; $\mathrm{O}_{3}$ : Ozone; $\mathrm{PM}_{2.5}$ : Particulate matter with an aerodynamic diameter less than 2.5 micrometers; $\mathrm{PM}_{10}$ : Particulate matter with an aerodynamic diameter less than 10 micrometers; RCP: Representative Concentration Pathway; RR: Relative risk; SI: Sea ice; SMR: Standardised morbidity ratio; $\mathrm{SO}_{2}$ : Sulphur dioxide; SSTs: Sea surface temperatures; UK: United Kingdom; WHO: World Health Organisation

\section{Acknowledgements}

Not applicable.

\section{Funding}

The study was funded by the UK Engineering and Physical Sciences research council grant numbers EP/J107442/1 and EP/J017485/1. The funding body played no role in the design of the study and collection, analysis, and interpretation of data. The work of MD and $\mathrm{FMO}^{\prime} \mathrm{C}$ was also supported by the Joint BEIS/Defra Met Office Hadley Centre Climate Programme (GA01101).

\section{Availability of data and materials}

The analysis was implemented in R using the ST . CARadaptive ( ) function from the CARBayesST package available from https://cran.rproject.org. All data generated and analysed during this study are included in this published article, see the additional files section below.

\section{Authors' contributions}

FP undertook the analysis of the pollution-health effects and co-wrote the paper. DL supervised the analysis of the pollution-health effects and co-wrote the paper. LN and PA ran the AQUM model for modelling the present day and future air quality over the UK and provided the modelled data. They also provided input and understanding on interpretation of the results for the paper. MD and $\mathrm{FMO}^{\prime} \mathrm{C}$ ran the global and regional climate-composition models in which AQUM was nested. SM prepared the data and liaised with FP and $\mathrm{DL}$ on the analysis. SS consulted on the data analysis. CS analysed the hospital admissions data, provided the resulting statistics and contributed background information for the introduction of the paper. All authors read and approved the final manuscript. 


\section{Competing interests}

The authors declare that they have no competing interests.

\section{Consent for publication}

Not applicable.

\section{Ethics approval and consent to participate} Not applicable.

\section{Publisher's Note}

Springer Nature remains neutral with regard to jurisdictional claims in published maps and institutional affiliations.

\section{Author details}

${ }^{1}$ School of Mathematics and Statistics, University of Glasgow, G12 8QW, Glasgow, UK. ${ }^{2}$ Met Office, FitzRoy Road, EX1 3PB, Exeter, UK. ${ }^{3}$ Met Office Hadley Centre, FitzRoy Road, EX1 3PB, Exeter, UK. ${ }^{4}$ Mathematical Sciences, University of Southampton, Highfield, SO17 1BJ, Southampton, UK.

\section{Received: 29 October 2016 Accepted: 20 March 2017}

\section{Published online: 27 March 2017}

\section{References}

1. WHO: Ambient (outdoor) air quality and health: Fact sheet 313. 2014. http://www.who.int/mediacentre/factsheets/fs313/en/. Accessed Dec 2015.

2. Royal College of Physicians: Every breath we take: The lifelong impact of air pollution. 2016. https://www.rcplondon.ac.uk/projects/outputs/everybreath-we-take-lifelong-impact-air-pollution. Accessed Nov 2016.

3. Department for the Environment, Food and Rural Affairs: Updated projections for Nitrogen Dioxide $\left(\mathrm{NO}_{2}\right)$ compliance. 2015. https://uk-air.defra.gov.uk/assets/documents/no2ten/ 140708_N02_projection_tables_FINAL.pdf.

4. Olmo NRS, Saldiva PHN, Braga ALF, Lin CA, Santos UP, Pereira LAA. A review of low-level air pollution and adverse effects on human health: implications for epidemiological studies and public policy,. Clinics. 2011;66(4):681-90. doi:10.1590/S1807-59322011000400025.

5. Chang HH, Peng RD, Dominici F. Estimating the acute health effects of coarse particulate matter accounting for exposure measurement error, Biostatistics. 2011:12(4):637-52. doi:10.1093/biostatistics/kxr002.

6. Villeneuve PJ, Weichenthal SA, Crouse D, Miller AB, To T, Martin RV, van Donkelaar A, Wall C, Burnett RT. Long-term Exposure to Fine Particulate Matter Air Pollution and Mortality Among Canadian Women, Epidemiology. 2015. doi:10.1097/EDE.0000000000000294.

7. Beverland IJ, Robertson C, Yap C, Heal MR, Cohen GR, Henderson DEJ, Hart CL, Agius RM. Comparison of models for estimation of long-term exposure to air pollution in cohort studies. Atmos Environ. 2012;62:530-9. doi:10.1016/j.atmosenv.2012.08.001.

8. Maheswaran R, Haining RP, Brindley P, Law J, Pearson T, Fryers PR, Wise S, Campbell MJ. Outdoor air pollution and stroke in Sheffield, United Kingdom: a small-area level geographical study,. Stroke. 2005;36(2): 239-43. doi:10.1161/01.STR.0000151363.71221.12.

9. Elliott P, Shaddick G, Wakefield JC, de Hoogh C, Briggs DJ. Long-term associations of outdoor air pollution with mortality in Great Britain. Thorax. 2007;62(12):1088-94.

10. Lee D, Ferguson C, Mitchell R. Air pollution and health in Scotland: a multicity study. Biostatistics. 2009;10(3):409-23. doi:10.1093/biostatistics/kxp010

11. Haining R, Li G, Maheswaran R, Blangiardo M, Law J, Best N, Richardson $\mathrm{S}$. Inference from ecological models: estimating the relative risk of stroke from air pollution exposure using small area data,. Spat Spatio-temporal Epidemiol. 2010;1(2-3):123-31. doi:10.1016/j.sste.2010.03.006.

12. Pannullo F, Lee $D$, Waclawski $E$, Leyland AH. How robust are the estimated effects of air pollution on health? Accounting for model uncertainty using Bayesian model averaging. Spat Spatio-temporal Epidemiol. 2016;18:53-62. doi:10.1016/j.sste.2016.04.001.

13. Jerrett M, Buzzelli M, Burnett RT, DeLuca PF. Particulate air pollution, social confounders, and mortality in small areas of an industrial city. Soc Sci Med. 2005;60(12):2845-63. doi:10.1016/j.socscimed.2004.11.006.

14. Janes H, Dominici F, Zeger SL. Trends in Air Pollution and Mortality: an approach to the assessment of unmeasured confounding. Epidemiology. 2007;18(4):416-23. doi:10.1097/EDE.0b013e31806462e9.
15. Greven S, Dominici F, Zeger S. An Approach to the Estimation of Chronic Air Pollution Effects Using Spatio-Temporal Information. J Am Stat Assoc. 2011;106(494):396-406. doi:10.1198/jasa.2011.ap09392.

16. Lawson AB, Choi J, Cai B, Hossain M, Kirby RS, Liu J. Bayesian 2-Stage Space-Time Mixture Modeling With Spatial Misalignment of the Exposure in Small Area Health Data. J Agric Biol Environ Stat. 2012;17(3):417-41. doi:10.1007/s13253-012-0100-3.

17. Lee D, Sarran C. Controlling for unmeasured confounding and spatial misalignment in long-term air pollution and health studies Environmetrics. 2015:26(7):477-87. doi:10.1002/env.2348.

18. Rushworth A, Lee D, Mitchell R. A spatio-temporal model for estimating the long-term effects of air pollution on respiratory hospital admissions in Greater London. Spatial Spatio-temporal Epidemiol. 2014;10:29-38. doi:10.1016/j.sste.2014.05.001.

19. Lee D, Shaddick G. Spatial modeling of air pollution in studies of its short-term health effects. Biometrics. 2010;66(4):1238-46. doi:10.1111/j.1541-0420.2009.01376.x

20. Lee D, Mitchell R. Controlling for localised spatio-temporal autocorrelation in long-term air pollution and health studies. Stat Methods Med Res. 20141-19. doi:10.1177/0962280214527384.

21. Lee D. Using spline models to estimate the varying health risks from air pollution across Scotland,. Stat Med. 2012;31(27):3366-78. doi:10.1002/sim.5420.

22. García-Herrera R, Díaz J, Trigo RM, Luterbacher J, Fischer EM. A Review of the European Summer Heat Wave of 2003. Crit Rev Environ Sci Technol. 2010;40(4):267-306. doi:10.1080/10643380802238137.

23. Christidis N, Jones GS, Stott PA. Dramatically increasing chance of extremely hot summers since the 2003 European heatwave. Nat Climate Change. 2015;5(January):3-7. doi:10.1038/NCLIMATE2468.

24. Brown A, Milton S, Cullen M, Golding B, Mitchell J, Shelly A. Unified Modeling and Prediction of Weather and Climate: A 25-Year Journey. Bull Am Meteorol Soc. 2012;93(12):1865-77. doi:10.1175/BAMS-D-12-00018.1.

25. Savage NH, Agnew P, Davis LS, Ordóñez C, Thorpe R, Johnson CE, O'Connor FM, Dalvi M. Air quality modelling using the Met Office Unified Model (AQUM OS24-26): model description and initial evaluation. Geoscientific Model Dev. 2013;6(2):353-72. doi:10.5194/gmd-6-353-2013.

26. Neal LS, Agnew P, Moseley S, Ordóñez C, Savage NH, Tilbee M. Application of a statistical post-processing technique to a gridded operational, air quality forecast. Atmos Environ. 2014;98:385-93. doi:10.1016/j.atmosenv.2014.09.004

27. Naess $\varnothing$, Piro FN, Nafstad P, Smith GD, Leyland AH. Air pollution, social deprivation, and mortality: a multilevel cohort study. Epidemiology. 2007;18(6):686-94. doi:10.1097/EDE.0b013e3181567d14.

28. Maheswaran R, Pearson T, Smeeton NC, Beevers SD, Campbell MJ, Wolfe CD. Outdoor air pollution and incidence of ischemic and hemorrhagic stroke: a small-area level ecological study. Stroke. 2012;43(1): 22-7. doi:10.1161/STROKEAHA.110.610238.

29. Pirani M, Gulliver J, Fuller GW, Blangiardo M. Bayesian spatiotemporal modelling for the assessment of short-term exposure to particle pollution in urban areas. J Expo Sci Environ Epidemiol. 2014;24(3):319-27. doi:10.1038/jes.2013.85.

30. van Vuuren DP, Stehfest E, den Elzen MGJ, Kram T, van Vliet J, Deetman S, Isaac M, Goldewijk KK, Hof A, Beltran AM, Oostenrijk R, van Ruijven B. RCP2.6: Exploring the possibility to keep global mean temperature increase below 2??C. Clim Chang. 2011;109(1):95-116. doi:10.1007/s10584-011-0152-3.

31. Masui T, Matsumoto K, Hijioka Y, Kinoshita T, Nozawa T, Ishiwatari S, Kato E, Shukla PR, Yamagata Y, Kainuma M. An emission pathway for stabilization at $6 \mathrm{Wm}-2$ radiative forcing. Climatic Change. 2011;109(1): 59-76. doi:10.1007/s10584-011-0150-5.

32. Riahi K, Rao S, Krey V, Cho C, Chirkov V, Fischer G, Kindermann G, Nakicenovic N, Rafaj P. RCP 8.5-A scenario of comparatively high greenhouse gas emissions. Climatic Change. 2011;109(1):33-57. doi:10.1007/s10584-011-0149-y.

33. Collins WJ, Bellouin N, Doutriaux-Boucher M, Gedney N, Halloran P, Hinton T, Hughes J, Jones CD, Joshi M, Liddicoat S, Martin G, O'Connor F, Rae J, Senior C, Sitch S, Totterdell I, Wiltshire A, Woodward S. Development and evaluation of an Earth-system model - HadGEM2. Geoscientific Model Dev. 2011;4:1051-75. doi:10.5194/gmd-4-1051-2011.

34. Jones CD, Hughes JK, Bellouin N, Hardiman SC, Jones GS, Knight J, Liddicoat S, O'Connor FM, Andres RJ, Bell C, Boo KO, Bozzo A, Butchart 
N, Cadule P, Corbin KD, Doutriaux-Boucher M, Friedlingstein P, Gornall J, Gray L, Halloran PR, Hurtt G, Ingram WJ, Lamarque JF, Law RM, Meinshausen M, Osprey S, Palin EJ, Parsons Chini L, RaddatzT, Sanderson MG, Sellar AA, Schurer A, Valdes P, Wood N, Woodward S, Yoshioka M, Zerroukat M. The HadGEM2-ES implementation of CMIP5 centennial simulations. Geosci Model Dev. 2011;4(3):543-70. doi:10.5194/gmd-4-543-2011.

35. Fiore AM, NaikV, Spracklen DV, Steiner A, Unger N, Prather M, Bergmann D, Cameron-Smith PJ, Cionni I, Collins WJ, Dalsøren S, Eyring V, Folberth GA, Ginoux P, Horowitz LW, Josse B, Lamarque JF, MacKenzie IA, Nagashima T, O'Connor FM, Righi M, Rumbold ST, Shindell DT, Skeie RB, Sudo K, Szopa S, Takemura T, Zeng G. Global air quality and climate. Chem Soc Rev. 2012;41 (19):6663. doi:10.1039/c2cs35095e.

36. Mackenbach JP, Kunst AE, Cavelaars AE, Groenhof F, Geurts JJ. Socioeconomic inequalities in morbidity and mortality in western Europe. The EU Working Group on Socioeconomic Inequalities in Health. Lancet. 1997;349(9066):1655-9.

37. Carder M, McNamee R, Beverland I, Elton R, Van Tongeren M, Cohen GR, Boyd J, Macnee W, Agius RM. Interacting effects of particulate pollution and cold temperature on cardiorespiratory mortality in Scotland,. Occup Environ Med. 2008;65(3):197-204. doi:10.1136/oem.2007.032896.

38. Rushworth A, Lee D, Sarran C. An adaptive spatiotemporal smoothing model for estimating trends and step changes in disease risk. J R Stat Soc Series C (Appl Stat). 2016. doi:10.1111/rssc.12155.

39. Leroux B, Lei X, Breslow N. Statistical Models in Epidemiology, the Environment and Clinical Trials In: Halloran M, Berry D, editors. Estimation of Disease Rates in Small Areas: A New Mixed Model for Spatial Dependence. New York: Springer; 2000. p. 135-78. doi:10.1007/978-1-4612-1284-3.

40. COMEAP: Quantification of Mortality and Hospital Admissions Associated with Ground-level Ozone: Public Health England; 2015. https://www.gov. uk/government/collections/comeap-reports. Accessed Dec 2015.

41. Huang G, Lee D, Scott M. An integrated Bayesian model for estimating the long-term health effects of air pollution by fusing modelled and measured pollution data: A case study of nitrogen dioxide concentrations in Scotland. Spatial Spatio-temporal Epidemiol. 2015. doi:10.1016/j.sste.2015.09.002.

42. Williams ML, Atkinson RW, Anderson HR, Kelly FJ. Associations between daily mortality in London and combined oxidant capacity, ozone and nitrogen dioxide. Air Qual Atmosphere Health. 2014;7(4):407-14. doi:10.1007/s11869-014-0249-8.

43. Lee D, Rushworth A, Sahu SK. A Bayesian localized conditional autoregressive model for estimating the health effects of air pollution Biometrics. 2014;70(2):419-29. doi:10.1111/biom.12156.

44. O'Neill BC, Tebaldi $C$, van Vuuren DP, Eyring V, Friedlingstein P, Hurtt $G$, Knutti R, Kriegler E, Lamarque JF, Lowe J, Meehl GA, Moss R, Riahi K, Sanderson BM. The Scenario Model Intercomparison Project (ScenarioMIP) for CMIP6. Geosci Model Dev. 2016;9(9):3461-482. doi:10.5194/gmd-9-3461-2016.

45. Blangiardo M, Finazzi F, Cameletti M. Two-stage Bayesian model to evaluate the effect of air pollution on chronic respiratory diseases using drug prescriptions. Spatial Spatio-temporal Epidemiol. 2016;0:1-12. doi:10.1016/j.sste.2016.03.001.

\section{Submit your next manuscript to BioMed Central and we will help you at every step:}

- We accept pre-submission inquiries

- Our selector tool helps you to find the most relevant journal

- We provide round the clock customer support

- Convenient online submission

- Thorough peer review

- Inclusion in PubMed and all major indexing services

- Maximum visibility for your research

Submit your manuscript at www.biomedcentral.com/submit 